\title{
Ablative therapies of the biliary tree
}

\author{
Elizabeth S. John, Paul R. Tarnasky, Prashant Kedia \\ Department of Gastroenterology, Methodist Dallas Medical Center, Dallas, TX, USA \\ Contributions: (I) Conception and design: All authors; (II) Administrative support: All authors; (III) Provision of study materials or patients: None; (IV) \\ Collection and assembly of data: ES John; (V) Data analysis and interpretation: None; (VI) Manuscript writing: All authors; (VII) Final approval of \\ manuscript: All authors. \\ Correspondence to: Elizabeth S. John. Department of Gastroenterology, Methodist Dallas Medical Center, Dallas, TX 75203, USA. \\ Email: Elizabethjohn@mhd.com.
}

\begin{abstract}
Cholangiocarcinoma, a malignancy of the epithelial cells in the intrahepatic or extrahepatic biliary tree, is often diagnosed at later stages. Median survival duration ranges from 3 to 9 months with a less than ten percent 5 -year survival rate. Thus, often treatment strategies are aimed more towards palliation instead of cure. With the majority of patients presenting with unresectable disease at the time of diagnosis, surgical intervention is not feasible, making less invasive endoscopic therapies more suitable. Initially, biliary stents were utilized for biliary decompression to mitigate cholestatic symptoms and prevent cholangitis; however, this strategy did not prove to provide significant survival benefit. Therefore, efforts to treat the tumor burden itself in addition to maintaining biliary patency became a focus of innovation and research in the endoscopic field. This study has led to the advent of therapies such as photodynamic therapy, radiofrequency ablation, and intraluminal brachytherapy. These options combined with biliary stenting have shown to not only offer the benefit of biliary decompression, but also to potentially improve stent patency and survival. Further, there is an anti-tumor effect of each of these modalities, portending an additional benefit in this subset of patients. Despite numerous retrospective and prospective studies assessing these ablative therapies, there is still a paucity of appropriately powered randomized controlled trials, and further research has yet to be done in the field. This review details the current literature entailing endobiliary ablative strategies.
\end{abstract}

Keywords: Photodynamic therapy; radiofrequency ablation; intraluminal brachytherapy; cholangiocarcinoma

Received: 12 December 2019; Accepted: 23 January 2020; Published: 25 October 2021.

doi: $10.21037 /$ tgh.2020.02.03

View this article at: http://dx.doi.org/10.21037/tgh.2020.02.03

\section{Introduction}

Ablative therapies of the biliary tree are typically utilized in the setting of malignant biliary obstruction, most commonly caused by cholangiocarcinoma (CCA) and pancreatic head cancer, but also by gallbladder cancer, ampullary cancer, malignant hilar lymphadenopathy, and hepatocellular carcinoma (1). Specifically, CCA, a malignancy of epithelial cells of the intrahepatic or extrahepatic biliary tree, presents as unresectable disease in $60-80 \%$ of patients at the time of diagnosis (2). In these patients, the 5 -year survival is $5-10 \%$, and the median survival duration ranged from 3 to 9 months (3). Thus in the majority of these cases, treatment is aimed at palliation as opposed to cure. Endoscopists play a significant role in palliation of these patients by achieving and maintaining biliary patency via performance of endoscopic retrograde cholangiopancreatography (ERCP). The goals of biliary decompression are multiple including preservation of hepatic function, abatement of symptoms associated with cholestasis (i.e., pruritis, jaundice) and prevention of cholangitis. Biliary stent placement alone has not been associated with significantly improved survival $(4,5)$. This has allowed for the emergence and study of endobiliary ablative technologies such as photodynamic therapy (PDT), radiofrequency ablation (RFA) and intraluminal brachytherapy (IB) as complementary treatment modalities to potentiate the goals of biliary 
Table 1 Review of trials investigating effect of photodynamic therapy on survival outcomes in patients with unresectable CCA

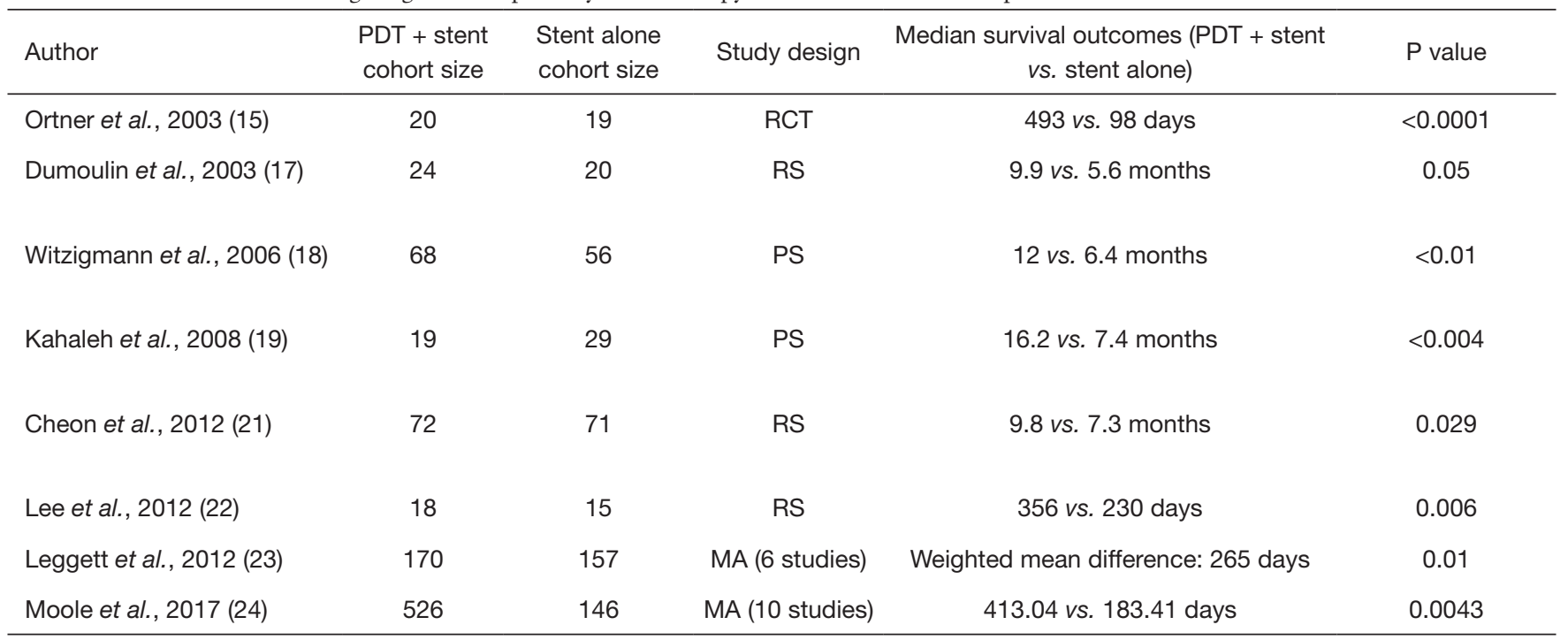

CCA, cholangiocarcinoma; PDT, photodynamic therapy; RCT, randomized controlled trial; RS, retrospective study; PS, prospective study; MA, meta-analysis.

decompression and provide additional benefits of longer stent patency and improved survival.

\section{Endoscopic retrograde cholangiopancreatography-guided}

\section{Photodynamic therapy}

PDT is an ablative technology that utilizes an intravenous photosensitizing agent, to provoke biliary neoplastic cells that then become vulnerable to light-induced photoactivation and subsequent apoptosis. Porfimer sodium is the most commonly used agent in the United States. Though it has not yet been approved for CCA, it is still covered by most insurers for compassionate use $(6,7)$. Other photosensitizing agents not available in the U.S. include meta-tetrahydroxyphenyl chlorine, hematoporphyrin derivatives (Photogem, Photoscan-3), and mesotetrahydroxyphenylchlorin (8).

After porfimer sodium is intravenously administered, the substance is nonspecifically absorbed by cells of numerous tissues, but it is highly concentrated in malignant biliary epithelium due to its strong predilection for these cells. At 48 to 72 hours, the patient undergoes ERCP with cholangiogram, during which a diode laser fiber with a cylindrical diffuser at the distal-most end is positioned in the biliary tree across the target lesion or stricture. Once in the proper position, the laser fiber is illuminated to a specific wavelength (generally $630 \mathrm{~nm}$ ) for 750 seconds, which triggers a photoperoxidation reaction and generation of oxygen free radicals $(9,10)$. This leads to membrane fluidity loss, DNA damage, DNA repair inhibition, mitochondrial activity destruction, and lysosomal and nuclear damage, all of which ultimately produce tissue necrosis and apoptosis. Additionally, PDT also activates inflammatory cascades and anti-angiogenic pathways that also assist in local tumor control (11-13). An additional benefit of PDT is that the light waves are capable of refracting through the bile, reaching proximal portions of the biliary tree that are beyond the reach of the fiber itself (11). Stent placement is subsequently performed as the inflammation and edema from PDT's destruction of tumor cells potentially causes biliary obstruction and cholangitis (8).

Preliminary descriptions of PDT were case reports and anecdotally since 1991 (14). A landmark trial studying PDT in 39 patients with unresectable CCA was performed in 2003. Patients were randomized to either receive PDT 48 hours prior to ERCP with stenting $(n=20)$ or stenting alone $(n=19)$. The patients who underwent unilateral or bilateral PDT with stenting had significantly longer median survival (493 vs. 98 days, $\mathrm{P}<0.0001$ ), increased biliary drainage, and a significantly better life quality compared to those who were treated only by stent placement (15). Subsequent studies have showed improvement in overall survival in patients with unresectable CCA (16-22) (Table 1). 
Since then, a meta-analysis assessed PDT in 170 patients with CCA over 6 studies. PDT plus stenting was associated with a significantly longer survival (265 days; $95 \%$ CI: $154-376$ days, $\mathrm{P}=0.01$ ), augmented performance status as per their Karnofsky scores (weighted mean difference 7.74; 95\% CI: 3.73-11.76; $\mathrm{P}=0.01$ ), and a similar pooled event rate specifically with regards to biliary sepsis (23). A more recent meta-analysis found significant improvement in survival in patients with CCA who underwent PDT plus stenting ( $\mathrm{n}=526 ; 413.04$ days; $95 \%$ CI: $349.54-$ 476.54) versus those who received stenting alone $(n=146$; 183.41 days; 95\% CI: 136.81-230.02). The generalizability of the study was hindered by its heterogeneity with percutaneous and endoscopic administration of PDT and both percutaneously or endoscopically placed biliary stents in the included studies (24). One randomized trial found worse survival outcomes in the PDT group compared to group treated with only a stent (median $6.2 \mathrm{vs} .9 .8$ months; HR $1.56,95 \%$ CI: 1.00 to $2.43, \mathrm{P}=0.048$ ). Progression free survival was also worse in the PDT group (median 3.4 vs. 4.3 months; HR 1.43, 95\% CI: 0.93 to $2.18, \mathrm{P}=0.10$ ). Interpretation of this study, however, was limited by the difference of chemotherapy regimens in the two groups (25).

In addition to survival outcomes, studies have also examined the role of PDT in stent patency, predictors that could portend a better prognosis after PDT, and the impact of PDT prior to and after surgical resection. Specifically, one study looked at 33 unresectable CCA patients, 18 of whom had PDT and uncovered metal stents and 15 of whom were treated with uncovered metal stents alone. Those who received PDT had significantly longer stent patency (median $244+/-66$ vs. $177+/-45$ days; $\mathrm{P}=0.002$ ) and survival (median $356+/-213$ vs. $230+/-73$ days; $\mathrm{P}=0.006$ ) (22). With regards to predictive factors, Prasad et al. identified 25 patients with unresectable CCA that received PDT endoscopically and percutaneously as well as biliary stenting. Increased mortality was associated with a longer time before PDT administration (HR 1.13; 95\% CI: $1.02-1.25 ; \mathrm{P}=0.029$ ), imaging with an appreciable mass (HR 3.55; 95\% CI: $1.21-10.38 ; \mathrm{P}=0.021)$, and lower albumin (HR 0.16; 95\% CI: 0.04-0.59; $\mathrm{P}=0.005$ ) (26). PDT prior to surgical resection was also studied in 7 patients in an attempt to downstage unresectable CCA.

There were no significant differences in overall survival between 7 patients with PDT followed by surgical resection in 30-72 days compared to 35 patients with surgical resection alone (27).

Several studies have looked at the effects of combination therapy with systemic chemotherapy and PDT. Most recently, a retrospective analysis from 2019 investigated the role of combination therapy in 96 patients with unresectable perihilar CCA and distal CCA. 34 patients underwent PDT (photoactive compounds porfimer, hematoporphyrin, and temoporfin), 26 patients underwent chemotherapy (mostly gemcitabine based), and 36 patients underwent PDT and chemotherapy. There was a trend towards increased median overall survival in patients who received PDT plus chemotherapy (20 months, 95\% CI: 16.38-23.62) compared to the PDT group (15 months, 95\% CI: 10.02-19.98) and the chemotherapy alone group (10 months, $95 \%$ CI: $8.45-$ 11.55) (28). A previous retrospective analysis of patients with perihilar CCA after biliary stenting investigated PDT $(n=35)$ versus PDT and chemotherapy $(n=33)$. The mean overall survival in those who underwent PDT plus chemotherapy was significantly longer than the PDT group alone (520 vs. 374 days, respectively; $\mathrm{P}=0.021$ ), with similar rates of cholangitis (29). A prospective, randomized, phase II trial explored the effects of oral fluoropyrimidine S-1 to PDT in unresectable CCA. Those receiving combination therapy had a longer overall median survival (17 vs. 8 months, $\mathrm{P}<0.005)$, and a longer median progressionfree survival (10 vs. 2 months, $\mathrm{P}=0.009)$. With regards to feasibility, systemic chemotherapy and PDT is tolerable. A phase II trial of PDT and gemcitabine/capecitabine (GemCap) examined 20 patients with recurrent or metastatic bile tract cancers including CCA and gallbladder cancers. Ten patients received PDT, GemCap, and biliary stents while 10 patients received only GemCap and biliary stents. There were no significant differences in the quality of life as measured by the EORTC QLQ-C30 score (30). Again, these trials are limited by their small sample sizes, and interpreted with caution, but generally it seems that PDT may have an additive benefit to chemotherapy in terms of overall survival (Table 1).

\section{Adverse events/limitations}

The most common side effect of PDT is phototoxicity as the photosensitizer absorption is not restricted to malignant biliary epithelial cells. Other skin effects include erythema, pruritus, blistering, and diffuse pain. Patients are typically educated on avoiding direct sunlight for 4-6 weeks post PDT, which can severely minimize patients' life quality when the life expectancy is also truncated due to incurable malignancies that are prompting the PDT therapy in the first place $(4,8)$. Biliary obstruction can theoretically occur from localized tissue edema, however, studies have shown 
that PDT might not necessarily increase the risk of biliary sepsis. Nonetheless, endoscopic biliary stenting after PDT is recommended $(8,23)$. From a practical standpoint, the fiber optic laser diffuser is expensive, with the specific Optiguide DCYL700 fiber optic model priced at $\$ 850$ U.S. dollars. Furthermore, the average-wholesale cost of one $75-\mathrm{mg}$ vial of porfimer sodium was $\$ 24,512$, which is half the total amount an average 75 kilogram patient would require. Another practical hindrance is the three-day gap required after administration of the photosensitizer before treatment with PDT can be accomplished (31). Other logistical challenges of the procedure include procurement of the laser tower itself and time commitments of the procedure especially if multiple applications are planned in a single setting.

\section{Endoscopic retrograde cholangiopancreatography-guided}

\section{Radiofrequency ablation (RFA)}

The utilization of electric currents to generate heat has been employed in medicine since the early 1900s. Specifically, RFA applies an alternating current that creates electromagnetic wave frequencies ranging from $10^{4}$ to $3 \times 10^{12} \mathrm{~Hz}$ (32). This subsequently heats tissue, causes protein coagulation, and destructs tissue (33). It has been purported that RFA might induce indirect anti-tumor effects including T-lymphocyte activation and localized inflammatory response stimulation, both of which are recognized after RFA treatment of other malignancies (34-38). From a technical standpoint, the success of RFA can be limited by substances that conduct current poorly such as charred tissue, vapor and gas, and by blood flow in the target tissues which serve as heat sinks (39). Nonetheless, RFA has become a viable option in the evolving management of perihilar and extrahepatic CCA, benign biliary strictures, and ampullary neoplasms. Currently the only approved biliary RFA catheter in the United States the Habib catheter (Boston Scientific, Natick, MA). This is an 8 French catheter with two 8 millimeter $(\mathrm{mm})$ ringed electrodes at the distal end of the catheter providing a 2.5 centimeter $(\mathrm{cm})$ elliptical range of ablation using a $7-10$ watt application for $60-120$ seconds. Other ablation catheters are available internationally including the ELRA system (STARmed, Goyang, Korea) which comes in various sizes and has a unique built in temperature monitoring system.

\section{Malignant biliary obstruction}

Steele et al. first reported in 2011 RFA as a therapeutic option for biliary decompression in unresectable malignant biliary obstruction. This open-label pilot study investigated 22 patients with pancreatic cancer $(\mathrm{PC}, \mathrm{n}=16)$ and CCA $(\mathrm{n}=6)$. Out of the 21 patients who received RFA with subsequent metal stent placement, 20 patients and 16 patients maintained biliary patency at 30 and 90 days, respectively (40). A retrospective study of 66 patients with biliary obstruction (CCA in 37 patients, $\mathrm{PC}$ in 27 patients) compared RFA and self-expanding metal stents (SEMS) with SEMS alone. The cohorts were controlled for age and diagnosis. There were no significant differences in bile duct diameter, survival, or adverse effects (41). These same authors went on to investigate RFA followed by stent placement and compared to data from the Surveillance, Epidemiology, and End Results database registry. There was improved survival in the RFA cohort (42). Kallis et al. compared 23 PC patients who received RFA and SEMS to 46 patients who underwent SEMS placement alone. The RFA cohort had a significantly higher survival of $226 v$ s. 123.5 days $(\mathrm{P}=0.01)(43)$.

Zheng et al. conducted a meta-analysis that included nine studies with 263 patients who had malignant biliary obstruction secondary to CCA (65.8\%), PC (29.3\%), other cancer types $(4.9 \%)$, or metastatic cancer $(1.5 \%)$. RFA significantly improved stricture diameter by $3.446 \mathrm{~mm}(95 \%$ CI: $3.356-3.536 \mathrm{~mm})$. There was a $17 \%$ (95\% CI: $10-25 \%)$ pooled rate of adverse events, with most complications being mild and managed conservatively, though two deaths from hemobilia and one case of partial liver infarction also occurred (44).

A randomized controlled trial published in 2018 describing 65 patients with types I and II Klatskin tumors $(n=19)$ and distal CCA $(n=46)$ that were randomized to RFA and plastic stent $(n=32)$ and plastic stent $(n=33)$. Stent patency and overall survival time were significantly longer in the RFA plus stent cohort, 6.8 vs. 3.4 months, $\mathrm{P}=0.02$ and $13.2+/-0.6$ vs. $8.3+/-0.5$ months, $\mathrm{P}<0.001$, respectively. Multivariable Cox regression analysis showed that RFA was the main protective factor in patients' survival $(\mathrm{P}<0.001)$. The incidence of adverse events was similar in each group (45). Similarly, a recent systematic review of nine studies investigated the outcomes of endoscopically or percutaneously administered RFA with stent placement compared to stent placement alone in 505 patients with 
malignant biliary strictures. Patients who received RFA had longer stent patency of 50.6 days (95\% CI: 32.83-68.48) and improved survival (hazard ratio, $1.395 ; 95 \% \mathrm{CI}$ : $1.145-1.7 ; \mathrm{P}<0.001)$. There were no significant differences in post-procedural adverse events including cholangitis, acute cholecystitis, pancreatitis, and hemobilia, though patients who received RFA had a significantly higher risk of post-procedural abdominal pain $(31 \%$ vs. $20 \%$, $\mathrm{P}=0.003)(46)$.

While RFA is an FDA-approved technology, the generalizability of these studies is limited by the small number of patients, the observational designs of the majority of the studies, the heterogeneity in the study population (i.e., inclusion of PC and CCA induced biliary strictures), and route of RFA administration (i.e., percutaneously and endoscopically). Nonetheless, it has thus far shown to be an effective modality for improving stent patency and survival and merits further study.

\section{Benign biliary strictures}

These strictures can arise from a wide array of causes including, but not limited to, hypoperfusion during liver transplantation, post-operative bile duct injury, chronic bile duct inflammation or chronic pancreatitis (47). Pathogenesis of benign biliary strictures (BBS) is related to fibrous tissue hyperplasia causing narrowing of the duct lumen (48). Stents, both plastic and SEMS, are comparable in terms of clinical success (49), but consequent stricturing is a significant problem (50). It has been postulated that the thermal effect of RFA can alter the fibrous scar tissue, improving the efficacy of subsequent endoscopic therapy more efficacious in the future. A prospective study conducted in 2014 explored the role of RFA in 9 patients with refractory BBS due to post-operative complications $(\mathrm{n}=4)$, post-anastomotic after liver transplantation $(\mathrm{n}=3)$, chronic inflammatory strictures $(\mathrm{n}=1)$, and obstructive tissue hyperplasia inside a previously placed SEMS for chronic pancreatitis $(n=1)$. About $80 \%$ of patients already failed previous endoscopic or percutaneous interventions. RFA was performed with balloon dilation post-ablation. Plastic or SEMS were placed if there was no stricture resolution post treatment. Five patients had stricture resolution, and 4 patients had stricture improvement after RFA application. Further stenting was not requisite in 3 cases. The patient with tissue hyperplasia inside a previously placed SEMS required surgery for stent retrieval, but did have good biliary drainage post-ablation. Adverse events included, mild post-procedural pain $(n=2)$, mild post-procedural acute pancreatitis $(n=1)$, and transient leukocytosis $(n=2)$. More studies, certainly of larger sizes, would be helpful in making further conclusions about the safety and efficacy of RFA application in BBS (51).

\section{Ampullary neoplasm}

Despite advances in the endoscopic therapies of ampullary adenomas, the management of intraductal extension has remained challenging. Traditionally, involvement of the biliary or pancreatic ducts has been an indication for surgical management. However, ampullectomy and pancreaticoduodenectomy are associated with significant morbidity and mortality, making recent evolutions in minimally invasive options such as RFA attractive (52). Also, some patients with intraductal extension of ampullary neoplasms are not fit for surgery and may not have adequate therapeutic options.

A small case series reported that 3 of 4 patients had complete eradication of intraductal residue without any immediate adverse events in the immediate setting (53). A retrospective multicenter study evaluated the efficacy, feasibility, and safety of RFA for ampullary neoplasms with intraductal extension in 14 patients. These patients underwent a median of one RFA session (range 1-5 sessions), and at a median follow-up of 16 months, complete intraductal ablation was accomplished in $91.6 \%$ of patients. There was a $43 \%$ adverse event rate, which included ductal strictures and a retroduodenal abscess, both of which were successfully treated endoscopically (54).

A prospective open-label multicenter study examined twenty patients with endobiliary adenomas, of which fifteen were low grade dysplasia and five were high grade dysplasia. All patients underwent one successful RFA treatment and biliary stent placement with an uneventful recovery. The rates of residual neoplasia were $15 \%(3 / 20)$ and $30 \%(6 / 20)$ at 6 and 12 months, respectively. $40 \%$ $(8 / 20)$ had at least one adverse during follow up, mild pancreatitis melena while on clopidogrel, cholangitis, and biliary strictures (55).

Though these studies are limited by their sample sizes, they document efficacy of RFA with a relatively minimal side effect profile, suggesting this could be a viable 
alternative to surgery. Post-ablation pancreatitis is likely the most significant concern for performing RFA in this region and techniques to minimize this adverse event (i.e., prophylactic pancreas duct stenting, non-steroidal antiinflammatory medications) will need to be optimized. Nonetheless, the limited study sizes and the scarce number of studies regarding this application make further investigation requisite.

\section{Adverse effects}

RFA has shown to have a relatively low incidence of significant adverse events, though more serious side effects have been reported. The main adverse events include abdominal pain, pancreatitis, cholangitis, cholecystitis, most of which were shown to be mild and managed conservatively $(41,43,44,56)$. However, the two deaths from hemobilia, one case of partial liver infarction, and one hepatic artery pseudoaneurysm are major adverse events thought to be secondary to RFA use in intrahepatic biliary segments leading to vascular injuries of branches of the hepatic artery (44,57-59). Subsequently lower energy settings for intrahepatic use of RFA are recommended by experts.

\section{Intraluminal brachytherapy}

Intraluminal brachytherapy (IB) entails using iridium-192 (192Ir) or iodine-125 (125I) seeds contained in a ribbon or a wire that is advanced into the biliary lumen via a trans-hepatic approach and a trans-duodenal endoscopic technique. In the endoscopic technique, ERCP identifies the site of the tumor, the length of bile duct involved, and the extent of disease. A guide wire is advanced through the malignant stricture, after which the endoscope is removed and a naso-biliary tube is threaded over the guidewire into the biliary tree. An afterloading catheter that contains the radio-opaque marker wire is passed under fluoroscopy through the naso-biliary tube. The radio-opaque wire has markers at intervals to specify the position where the radioactive source should be placed. Radiographic confirmation is performed (60). The trans-hepatic approach is preferable and can provide internal drainage across the tumor as well as external drainage (61). IB causes directly destructs DNA, inhibits cellular replication, and induces apoptosis of tumor cells $(60,62)$.

First reported in 1981 (63), multiple subsequent studies have attempted to validate the efficacy of this modality with regards to stent patency and overall survival in CCA. Their small sample sizes, heterogeneous prior treatment approaches, and different cancer types causing biliary obstruction make interpretation difficult (64). A metaanalysis of 12 studies in 2018 compared outcomes in those with malignant biliary obstruction who underwent IB and stenting ( $\mathrm{n}=340$ patients) versus stenting alone $(\mathrm{n}=301$ patients). Patients with IB and stenting experienced less stent occlusion (odds ratio, 0.19; 95\% CI: 0.13-0.28; $\mathrm{P}<0.00001$ ) and prolonged mean survival (mean difference, 3.15 months; 95\% CI: 2.64-3.66 months; $\mathrm{P}<0.0001$ ) without significant differences in adverse events or changes in bilirubin levels (62). IB has also been studied in patients with unresectable CCA undergoing neoadjuvant chemotherapy as a bridge therapy to liver transplantation (65).

The usage of IB is hindered by practical inconveniences and adverse effects of the therapy. As the material is radioactive and has a short half-life, there are logistical challenges in handling, storing, and delivering the substances. Immediate adverse events include biliary obstruction, cholangitis, and hemobilia, whereas delayed complications include gastrointestinal bleeding, duodenal stenosis, and hemobilia, all of which are direct results of radiation (60). PDT and RFA have largely replaced IB at the endoscopic ablative technologies of choice in malignant obstruction.

\section{Summary}

Malignant biliary obstruction very commonly becomes the responsibility of the advanced endoscopist to maintain patency for palliation given the low rate of curative resection of these lesions (66). While ERCP with serial stenting has long been the gold standard, ablative therapies including PDT, RFA, and IB have risen to prominence in this subset of patients because of the potential benefits of improved survival and stent patency in addition to the antitumor effects of each of the modalities (Figure 1). Though these options have emerged over the last two decades, better powered studies in more homogenously controlled cohorts are required to make more informed decisions about the application of these technologies (Table 2). 

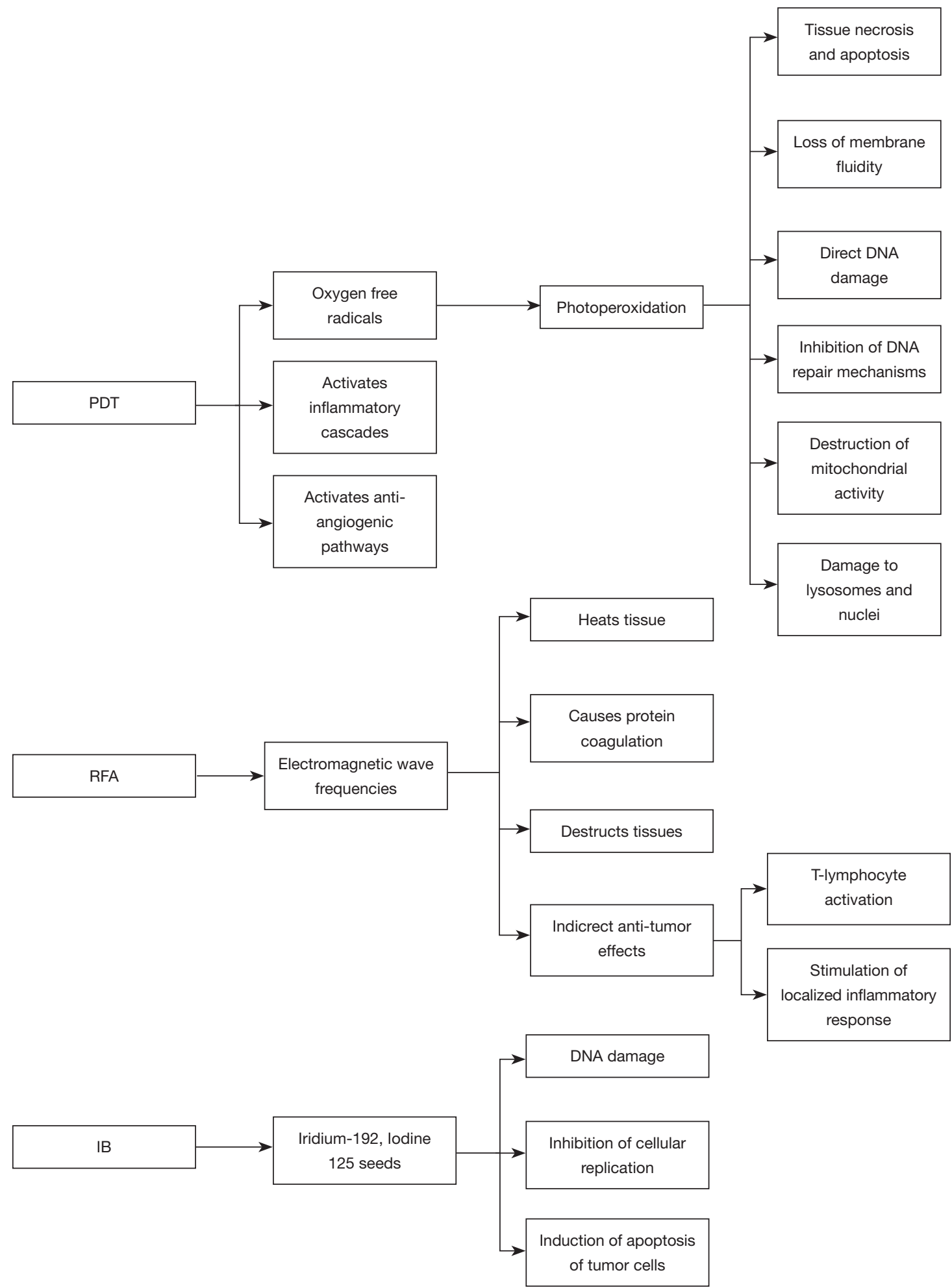

Figure 1 The pathophysiology of each ablative therapy. PDT, photodynamic therapy, RFA, radiofrequency ablation; IB, intraluminal brachytherapy. 
Table 2 This table summarizes the outcomes compared to stents alone, adverse effects, and practical considerations to take into account prior to application

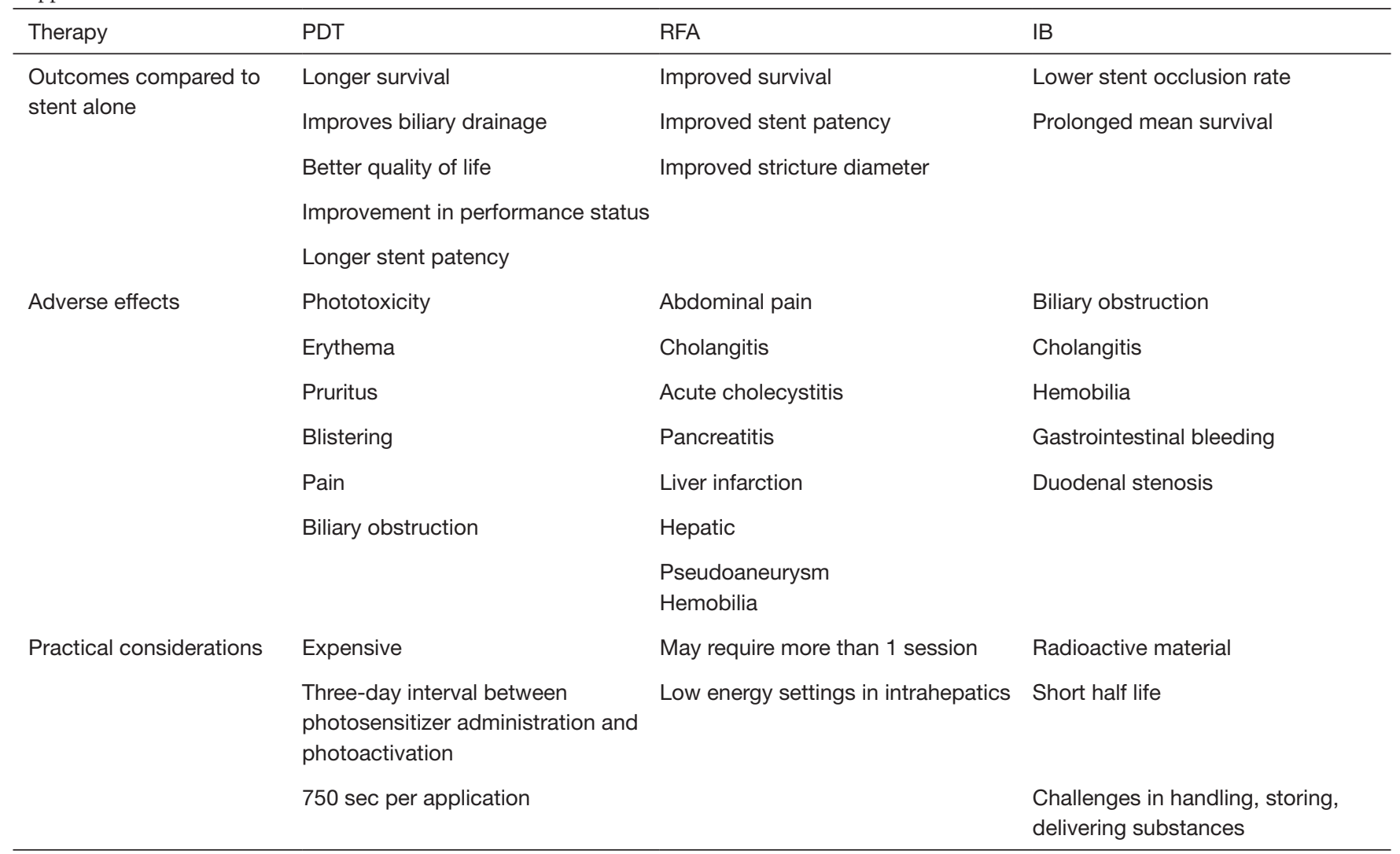

PDT, photodynamic therapy; RFA, radiofrequency ablation; IB, intraluminal brachytherapy.

\section{Acknowledgments}

We would like to acknowledge the editors for inviting us to participate in this review article.

Funding: None.

\section{Footnote}

Provenance and Peer Review: This article was commissioned by the Guest Editor (Amy Tyberg) for the series "Innovation in Endoscopy" published in Translational Gastroenterology and Hepatology. The article has undergone external peer review.

Conflicts of Interest: ESJ has no conflicts of interest. PRT has a consulting agreement with Boston Scientific. PK has consulting agreements with Boston Scientific, Olympus, and Medtronic.

Ethical Statement: The authors are accountable for all aspects of the work in ensuring that questions related to the accuracy or integrity of any part of the work are appropriately investigated and resolved.

Open Access Statement: This is an Open Access article distributed in accordance with the Creative Commons Attribution-NonCommercial-NoDerivs 4.0 International License (CC BY-NC-ND 4.0), which permits the noncommercial replication and distribution of the article with the strict proviso that no changes or edits are made and the original work is properly cited (including links to both the formal publication through the relevant DOI and the license). See: https://creativecommons.org/licenses/by-nc-nd/4.0/.

\section{References}

1. Dawwas MF, Oppong KW, Webster GJ. Endoscopic assessment and management of biliary strictures. Frontline Gastroenterol 2016;7:170-5. 
2. Razumilava N, Gores GJ. Cholangiocarcinoma. Lancet 2014;383:2168-79.

3. Boulay BR, Birg A. Malignant biliary obstruction: from palliation to treatment. World J Gastrointest Oncol 2016;8:498-508.

4. Lu Y, Liu L, Wu JC, et al. Efficacy and safety of photodynamic therapy for unresectable cholangiocarcinoma: a meta-analysis. Clin Res Hepatol Gastroenterol 2015;39:718-24.

5. Kaassis M, Boyer J, Dumas R, et al. Plastic or metal stents for malignant stricture of the common bile duct? Results of a randomized prospective study. Gastrointest Endosc 2003;57:178-82.

6. Yachimski P, Puricelli WP, Nishioka NS. Patient predictors of histopathologic response after photodynamic therapy of Barrett's esophagus with high-grade dysplasia or intramucosal carcinoma. Gastrointest Endosc 2009;69:205-12.

7. Food and Drug Administration. Photofrin injection label, 2011. Available online: https://www.accessdata.fda.gov/ drugsatfda_docs/label/2011/020451s020lbl.pdf. Accessed October 6, 2019.

8. Patel J, Rizk N, Kahaleh M. Role of photodynamic therapy and intraductal radiofrequency ablation in cholangiocarcinoma. Best Pract Res Clin Gastroenterol 2015;29:309-18.

9. Talreja JP, Degaetani M, Ellen K, et al. Photodynamic therapy in unresectable cholangiocarcinoma: not for the uncommitted. Clin Endosc 2013;46:390-4.

10. Talreja JP, Kahaleh M. Photodynamic therapy for cholangiocarcinoma. Gut Liver 2010;4:S62-6.

11. Uppal DS, Wang AY. Cholangiocarcinoma: endoscopic therapies. Tech Gastrointest Endosc 2016;18:83-90.

12. Skupin-Mrugalska P, Sobotta L, Kucinska M, et al. Cellular changes, molecular pathways and the immune system following photodynamic treatment. Curr Med Chem 2014;21:4059-73.

13. Henderson BW, Dougherty TJ. How does photodynamic therapy work? Photochem Photobiol 1992;55:145-57.

14. McCaughan JS Jr, Mertens BF, Cho C, et al. Photodynamic therapy to treat tumors of the extrahepatic biliary ducts. A case report. Arch Surg 1991;126:111-3.

15. Ortner ME, Caca K, Berr F, et al. Successful photodynamic therapy for nonresectable cholangiocarcinoma: a randomized prospective study. Gastroenterology 2003;125:1355-63.

16. Zoepf T, Jakobs R, Arnold JC, et al. Palliation of nonresectable bile duct cancer: improved survival after photodynamic therapy. Am J Gastroenterol 2005;100:2426-30.

17. Dumoulin FL, Gerhardt T, Fuchs S, et al. Phase II study of photodynamic therapy and metal stent as palliative treatment for nonresectable hilar cholangiocarcinoma. Gastrointest Endosc 2003;57:860-7.

18. Witzigmann H, Berr F, Ringel U, et al. Surgical and palliative management and outcome in 184 patients with hilar cholangiocarcinoma: palliative photodynamic therapy plus stenting is comparable to $\mathrm{r} 1 / \mathrm{r} 2$ resection. Ann Surg 2006;244:230-9.

19. Kahaleh M, Mishra R, Shami VM, et al. Unresectable cholangiocarcinoma: comparison of survival in biliary stenting alone versus stenting with photodynamic therapy. Clin Gastroenterol Hepatol 2008;6:290-7.

20. Quyn AJ, Ziyaie D, Polignano FM, et al. Photodynamic therapy is associated with an improvement in survival in patients with irresectable hilar cholangiocarcinoma. HPB (Oxford) 2009;11:570-7.

21. Cheon YK, Lee TY, Lee SM, et al. Longterm outcome of photodynamic therapy compared with biliary stenting alone in patients with advanced hilar cholangiocarcinoma. HPB (Oxford) 2012;14:185-93.

22. Lee TY, Cheon YK, Shim CS, et al. Photodynamic therapy prolongs metal stent patency in patients with unresectable hilar cholangiocarcinoma. World J Gastroenterol 2012;18:5589-94.

23. Leggett CL, Gorospe EC, Murad MH, et al. Photodynamic therapy for unresectable cholangiocarcinoma: a comparative effectiveness systematic review and metaanalyses. Photodiagnosis Photodyn Ther 2012;9:189-95.

24. Moole H, Tathireddy H, Dharmapuri S, et al. Success of photodynamic therapy in palliating patients with nonresectable cholangiocarcinoma: a systematic review and meta-analysis. World J Gastroenterol 2017;23:1278-88.

25. Pereira SP, Jitlal M, Duggan M, et al. PHOTOSTENT-02: porfimer sodium photodynamic therapy plus stenting versus stenting alone in patients with locally advanced or metastatic biliary tract cancer. ESMO Open 2018;3:e000379.

26. Prasad GA, Wang KK, Baron TH, et al. Factors associated with increased survival after photodynamic therapy for cholangiocarcinoma. Clin Gastroenterol Hepatol 2007;5:743-8.

27. Wagner A, Wiedmann M, Tannapfel A, et al. Neoadjuvant down-sizing of hilar cholangiocarcinoma with photodynamic therapy--long-term outcome of a phase ii pilot study. Int J Mol Sci 2015;16:26619-28. 
28. Gonzalez-Carmona MA, Bolch M, Jansen C, et al. Combined photodynamic therapy with systemic chemotherapy for unresectable cholangiocarcinoma. Aliment Pharmacol Ther 2019;49:437-47.

29. Wentrup R, Winkelmann N, Mitroshkin A, et al: Photodynamic therapy plus chemotherapy compared with photodynamic therapy alone in hilar nonresectable cholangiocarcinoma. Gut Liver 2016;10:470-5.

30. Hauge T, Hauge PW, Warloe T, et al. Randomised controlled trial of temoporfin photodynamic therapy plus chemotherapy in nonresectable biliary carcinomaPCS Nordic study. Photodiagnosis Photodyn Ther 2016;13:330-3.

31. Buerlein RCD, Wang AY, et al. Endoscopic Retrograde Cholangiopancreatography-Guided Ablation for Cholangiocarcinoma. Gastrointest Endosc Clin N Am 2019;29:351-67.

32. Ni Y, Mulier S, Miao Y, et al. A review of the general aspects of radiofrequency ablation. Abdom Imaging 2005;30:381-400.

33. Navaneethan U, Thosani N, Goodman A, et al. Radiofrequency ablation devices. VideoGIE 2017;2:252-9.

34. Hansler J, Wissniowski TT, Schuppan D, et al. Activation and dramatically increased cytolytic activity of tumor specific $T$ lymphocytes after radio-frequency ablation in patients with hepatocellular carcinoma and colorectal liver metastases. World J Gastroenterol 2006;12:3716-21.

35. Schueller G, Kettenbach J, Sedivy R, et al. Heat shock protein expression induced by percutaneous radiofrequency ablation of hepatocellular carcinoma in vivo. Int J Oncol 2004;24:609-13.

36. Haen SP, Pereira PL, Salih HR, et al. More than just tumor destruction: immunomodulation by thermal ablation of cancer. Clin Dev Immunol 2011;2011:160250.

37. Rai R, Richardson C, Flecknell P, et al. Study of apoptosis and heat shock protein (HSP) expression in hepatocytes following radiofrequency ablation (RFA). J Surg Res 2005;129:147-51.

38. Ali MY, Grimm CF, Ritter M, et al. Activation of dendritic cells by local ablation of hepatocellular carcinoma. J Hepatol 2005;43:817-22.

39. Haemmerich D. Biophysics of radiofrequency ablation. Crit Rev Biomed Eng 2010;38:53-63.

40. Steel AW, Postgate AJ, Khorsandi S, et al. Endoscopically applied radiofrequency ablation appears to be safe in the treatment of malignant biliary obstruction. Gastrointest Endosc 2011;73:149-53.

41. Sharaiha RZ, Natov N, Glockenberg KS, et al.
Comparison of metal stenting with radiofrequency ablation versus stenting alone for treating malignant biliary strictures: is there an added benefit? Dig Dis Sci 2014;59:3099-102.

42. Sharaiha RZ, Sethi A, Weaver KR, et al. Impact of radiofrequency ablation on malignant biliary strictures: results of a collaborative registry. Dig Dis Sci 2015;60:2164-9.

43. Kallis Y, Phillips N, Steel A, et al. Analysis of endoscopic radiofrequency ablation of biliary malignant strictures in pancreatic cancer suggests potential survival benefit. Dig Dis Sci 2015;60:3449-55.

44. Zheng X, Bo ZY, Wan W, et al. Endoscopic radiofrequency ablation may be preferable in the management of malignant biliary obstruction: a systematic review and meta-analysis. J Dig Dis 2016;17:716-24.

45. Yang J, Wang J, Zhou H, et al. Efficacy and safety of endoscopic radiofrequency ablation for unresectable extrahepatic cholangiocarcinoma: a randomized trial. Endoscopy 2018;50:751-60.

46. Sofi AA, Khan MA, Das A, et al. Radiofrequency ablation combined with biliary stent placement versus stent placement alone for malignant biliary strictures: a systematic review and meta-analysis. Gastrointest. Endosc 2018;87:944-51.e1.

47. Costamagna G, Shah SK, Tringali A. Current management of postoperative complications and benign biliary strictures. Gastrointest Endosc Clin N Am 2003;13:635-48.

48. Parsi MA. Common controversies in management of biliary strictures. World J Gastroenterol 2017;23:1119-24.

49. Khan MA, Baron TH, Kamal F. Efficacy of selfexpandable metal stents in management of benign biliary strictures and comparison with multiple plastic stents: a metaanalysis. Endoscopy 2017;49:682-94.

50. Costamagna G, Familiari P, Tringali A, et al. Multidisciplinary approach to benign biliary strictures. Curr Treat Options Gastroenterol 2007;10:90-101.

51. $\mathrm{Hu} \mathrm{B}, \mathrm{Gao} \mathrm{DJ}, \mathrm{Wu} \mathrm{J}$, et al. Intraductal radiofrequency ablation for refractory benign biliary stricture: pilot feasibility study. Dig Endosc 2014;26:581-5.

52. Larghi A, Rimbaș M, Tringali A, et al. Endoscopic radiofrequency biliary ablation treatment: A comprehensive review. Dig Endosc 2019;31:245-55.

53. Suarez AL, Cote GA, Elmunzer BJ. Adjunctive radiofrequency ablation for the endoscopic treatment of ampullary lesions with intraductal extension (with video). Endosc Int Open 2016;4:E748-51. 
54. Rustagi T, Irani S, Reddy DN, et al. Radiofrequency ablation for intraductal extension of ampullary neoplasms. Gastrointest Endosc 2017;86:170-6.

55. Camus M, Napoléon B, Vienne A, et al. Efficacy and safety of endobiliary radiofrequency ablation for the eradication of residual neoplasia after endoscopic papillectomy: a multicenter prospective study. Gastrointest Endosc 2018;88:511-8.

56. Laquière A, Boustiere C, Leblanc S, et al. Safety and feasibility of endoscopic biliary radiofrequency ablation treatment of extrahepatic cholangiocarcinoma. Surg Endosc 2016;30:1242-8.

57. Lee YN, Jeong S,Choi HJ, et al. The safety of newly developed automatic temperature controlled endobiliary radiofrequency ablation system for malignant biliary strictures: A prospective multicenter study. J Gastroenterol Hepatol 2019;34:1454-59.

58. Topazian M, Levy MJ, Patel S, et al. Hepatic artery pseudoaneurysm formation following intraductal biliary radiofrequency ablation. Endoscopy 2013;45:E161-2.

59. Dolak W, Schreiber F, Schwaighofer H, et al. Endoscopic radiofrequency ablation for malignant biliary obstruction: a nationwide retrospective study of 84 consecutive applications. Surg Endosc 2014;28:854-60.

60. Skowronek J, Zwierzchowski G. Brachytherapy in the

doi: $10.21037 / \operatorname{tgh} .2020 .02 .03$

Cite this article as: John ES, Tarnasky PR, Kedia P. Ablative therapies of the biliary tree. Transl Gastroenterol Hepatol 2021;6:63. treatment of bile duct cancer - a tough challenge. J Contemp Brachytherapy 2017;9:187-95.

61. Skowronek J, Sowier A, Skrzywanek P. Intraluminal Pulsed Dose Rate (PDR) brachytherapy and trans-hepatic technique in treatment of locally advanced bile duct cancer - preliminary assessment. Rep Pract Radioth Oncol 2007;2:125-33.

62. $\mathrm{Xu} \mathrm{X,} \mathrm{Li} \mathrm{J,} \mathrm{Wu} \mathrm{J,} \mathrm{et} \mathrm{al.} \mathrm{A} \mathrm{systematic} \mathrm{review} \mathrm{and} \mathrm{meta-}$ analysis of intraluminal brachytherapy versus stent alone in the treatment of malignant obstructive jaundice. Cardiovasc Intervent Radiol 2018;41:206-17.

63. Benjamin IS, McPherson GA, Blumgart LH. Iridium-192 wire for hilar cholangiocarcinoma. Lancet 1981;2:582-3.

64. Mattiucci GC, Autorino R, D’Agostino GR, et al. Chemoradiation and brachytherapy in extrahepatic bile duct carcinoma. Crit Rev Oncol Hematol 2014;90:58-67.

65. Mukewar S, Gupta A, Baron TH, et al. Endoscopically inserted nasobiliary catheters for high dose-rate brachytherapy as part of neoadjuvant therapy for perihilar cholangiocarcinoma. Endoscopy 2015;47:878-83.

66. Nagino M, Ebata T, Yokoyama Y, et al. Evolution of surgical treatment for perihilar cholangiocarcinoma: a single-center 34-year review of 574 consecutive resections. Ann Surg 2013;258:129-40. 